\title{
PROJETO DE ARQUEOLOGIA SUBAQUÁTICA: O PATRIMÔNIO CULTURAL MARINHO DO ESTADO DE SANTA CATARINA
}

\author{
Alexandre Viana* \\ Narbal de Souza Correa* \\ Marcelo Lebarbechon Moura*
}

\begin{abstract}
O litoral catarinense possui uma história marítima ocorrida pari passu com a ocupação humana da região, desde há vários milênios até hoje. Os testemunhos jazem em inúmeros sítios arqueológicos terrestres e aquáticos, além dos registros em fontes escritas, iconografias ena história oral. Há um imenso patrimônio cultural subaquático a ser pesquisado e preservado, conforme as leis brasileiras e as normas do International Committee on the Underwater Cultural Heritage - ICUCH- ICOMOS/UNESCO (O'keefe 1996; Grenier 2001; Oxley e O'Regan 2001). Nessa linha, a ONG Programa de Arqueologia Subaquática (PAS) foi criada, sem fins lucrativos, para pesquisar e contribuir para proteger o patrimônio cultural subaquático de Santa Catarina, e para montar um centro de estudos e museu de tecnologia náutica, cultura marítima, vida dos habitantes da costa e dos trabalhadores do mar, a partir das perspectivas da Arqueologia Subaquática e Histórica.

O projeto inaugural do PAS é a escavação de um naufrágio no canto sudoeste da Praia dos Ingleses, município de Florianópolis, autorizado pela Marinha do Brasil ${ }^{2}$ em 2002, com anuência do Ministério da Cultura. ${ }^{3}$ Também está sendo
\end{abstract}

(*) ONG Programa de Arqueologia Subaquática. ongpas@ongpas.org

(1) Financiado pela Fundação de Ciência e Tecnologia do Estado de Santa Catarina (Termo de Contrato n. 01/2004); pela PETROBRÁS (PRONAC 045412 , processo $\mathrm{n}$. 01400.008793/04-05); patrocinado pelo Costão do Santinho Resort; pela UNIMED/Florianópolis, que faz a revisão médica periódica dos mergulhadores.

(2) Portaria n. 59/DPC, de 03/06/2003 (D.O.U. n. 11, seção 1, p. 7, de 16/01/2004).

(3) A Câmara Municipal de Florianópolis reconheceu a ONG PAS como de "utilidade pública" (Lei n. 6444/2004, de 05 de abril de 2004). autorizado pelo IPHAN em 2005 e segue a AGENDA21/Florianópolis, ${ }^{4}$ especialmente o Programa 23 ("Sítios Históricos e Arqueológicos”) voltado à preservação, pesquisa e turismo cultural. A preservação do sítio Praia dos Ingleses 1, como primeira alternativa sugerida pela Convenção sobre a Proteção do Patrimônio Cultural Subaquático, não foi contemplada devido aos fatores pós-deposicionais antrópicos e naturais, comuns no ambiente praial (Beltrame 1998; Pinder e Vallega 2003; Smith e Couper 2003; Vallega 2003). O casco de madeira foi degradado, não sendo visível sobre o solo marinho. Trabalha-se com a hipótese de que a embarcação, de procedência ibérica, naufragou ao redor de 1700 A.D., com toda sua equipagem e carga, e que o casco foi destruído e coberto pela dinâmica praial. O leme está aproximadamente alinhado norte-sul, indicando que o casco afundou com seu eixo principal paralelo à praia. Há marcas de fogo no leme, indicando que houve incêndio a bordo, antes de ele ser afetado pela dinâmica praial e pela biodeterioração. A escavação sistemática começou em março de 2004, a 50m da praia, a 3,8m de profundidade.

Ao invés da coleta de amostras, como sugere a Convenção, a escavação justifica-se pela:

1) ação das tempestades e das correntes que expõe partes do contexto arqueológico, às vezes levando objetos até a praia, às vezes expondo os objetos sobre o solo marinho,

(4) IPHAN (Processo 01510.00027/2005-28) e Contrato de Autorização (n. 52.000/2003-015/00 - DPC/Marinha do Brasil), acordado no dia 16 de dezembro de 2003, entre a Autoridade Naval, o Exmo. Sr. Ministro da Cultura e a ONGPAS. 
deixando-os à mercê das poitas, âncoras, redes de arrasto e dos freqüentadores da praia, principalmente no veraneio, quando a praia fica "lotada de gente" e aumenta o impacto sobre o sítio arqueológico

2) ação química, especialmente a corrosão dos materiais inorgânicos; a ação da fauna (microorganismos e teredos), que se alimentam dos materiais orgânicos expostos ocasionalmente pela dinâmica praial, como as madeiras da embarcação.

A pesquisa de naufrágios, como alternativa à preservação, é assegurada pela Declaração de Sofia: "AArqueologia é uma atividade pública, todos têm o direito de indagar sobre o passado para enriquecer suas próprias vidas, e qualquer ação que restrinja esse conhecimento é uma violação da autonomia pessoal". Neste sentido, o PAS foi criado considerando outra norma da Declaração, estabelecida para "assegurar que todas as investigações sejam explícitas em seus objetivos e metodologia e resultados previstos, para que a intenção de cada projeto seja transparente para todos". Seguindo o exemplo do tratamento dos naufrágios em águas britânicas, o PAS considera que "os objetivos de qualquer trabalho de escavação são para registrar, interpretar e publicar um sítio, onde quer que ele esteja. Uma publicação completa para que a qualidade do trabalho e do gerenciamento do sítio possa ser julgada" (Marsden 1994:156).

Também segue os "princípios fundamentais" da

\section{Carta do ICOMOS sobre a Proteção e Gestão}

do Patrimônio Arqueológico, onde a pesquisa visa alentar o acesso ao público, na instrução e conscientização preservacionista. ${ }^{5}$

O segundo projeto da ONG PAS é a elaboração da Carta Arqueológica do Patrimônio Cultural Subaquático do Estado de Santa Catarina, com o objetivo de localizar, inventariar e, junto com a Marinha do Brasil e o IPHAN, tomar decisões quanto à proteção e gerenciamento dos sítios arqueológicos, seguindo a legislação brasileira e as

(5) Na base do PAS, situada no embarcadouro do Costão do Santinho Resort (praia dos Ingleses), há uma exposição permanente e a apresentação de vídeo com 6 min sobre a escavação e o projeto, visitada gratuitamente por mais de 9.000 pessoas até março de 2005 . orientações do ICUCH, da AGENDA21 e dos exemplos bem sucedidos ao redor do mundo, como os parques subaquáticos italianos (Davidde 2002). Segue-se como modelo ${ }^{6}$ a "Carta arqueológica subaquática dos Açores” (Monteiro 2003), fruto do esforço conjunto entre a Direcção Regional da Cultura do Governo Regional dos Açores, o Centro Nacional de Arqueologia Náutica e Subaquática do Instituto Português de Arqueologia e o Institute of Nautical Archaeology da Texas A\&M University. Primeiro serão mapeados os naufrágios localizados pelas autoridades marítimas, por pescadores e pela equipe do PAS. Depois iniciarão as pesquisas em áreas piloto de tamanho variado, posicionadas e orientadas por D-GPS, através de surveys guiados por meios eletrônicos, com varreduras até a isóbata de 50 metros. ${ }^{7}$

É possível estabelecer, preliminarmente, uma tipologia histórica das navegações no litoral sulbrasileiro: 1) período pré-histórico; 2) exploração, conquista e colonização (1504-1730); 3) expedições de apresamento indígena (1530-1700); 4) arribadas da "carreira das Índias" (séculos XVI a XVIII); 5) "pirataria" (1585-1650); 6) cabotagem (1580-2004); 7) tráfico negreiro (1590-1850); 8) arribadas de barcos de companhias comerciais européias (1602-1800); 9) pesca artesanal (a partir da fundação dos núcleos europeus); 10) pesca industrial (a partir de 1746, com as estações baleeiras); 11) rotas comerciais internacionais (séculos XIX e XX); 12) vasos de guerra (séculos

(6) Também observamos o exemplo de outros projetos científicos, visando à preservação e o manejo dos sítios subaquáticos e do seu ambiente de entorno: 1) Golfo do México, EUA(Garrison 1989; Arnold III 1996; Arnold III, Oertling 1995; Pearson et al 2003); 2) África do Sul (Werz 1993); 3) Inglaterra (Allen 1994); 4) Sri-Lanka (Green e Devendra 1993); 5) Rússia e antiga União Soviética (Okorokov 1993); 6) Austrália (Kenderdine 1994); 7) Yemen (Prados 1994); 8) Irlanda (Quinn, Cooper e Willians 2000); 9) Malásia (Flecker 1996); 10) Itália (Davidde 2002); 11) Espanha (Negueruela 2000); 12) Alemanha (Schlichterle e Kramer, 1996).

(7) Será usado o magnetômetro de prótons (JW Fischer Pulse 12) para localizar metais no leito marinho. Posteriormente, serão usados o sonar de varrimento lateral (SVL) e o perfilador de sedimentos, formando um sistema integrado para ampliar a eficiência da busca no solo oceânico. Todos serão rebocados pelo Mr. Blake (embarcação tipo "trawler", 16m de comprimento e capacidade para 14 pessoas). 
XVIII, XIX e XX); 13) navegação recreativa (vela e motor, séculos XX e XXI). Essa tipologia ${ }^{8}$ é fruto de uma pesquisa histórica em andamento, dedicada a elaborar uma lista de embarcações e notícias de naufrágios na região (já foram levantadas 2.000 embarcações, entre 1504 e 1750). Pode-se, também, a priori, presumir que as evidências dividem-se entre as visíveis acima do leito marinho (p. ex.: sambaquis, estruturas portuárias, cascos metálicos) e as situadas dentro dos sedimentos do leito marinho (p. ex.: canoas, artefatos diversos, cascos deteriorados de madeira).

\section{A equipe do PAS}

A primeira etapa do projeto na Praia dos Ingleses foi concebida por uma equipe de experientes mergulhadores profissionais que, de modo autodidata e com orientação ocasional de arqueólogos vinculados à Marinha do Brasil, realizaram a prospecção para definir o local do naufrágio (2002) e iniciaram a escavação e a conservação dos artefatos (2004). Contudo, ao contrário dos chamados "pioneiros", aqueles "mergulhadores que aprenderam a ser arqueólogos pela tentativa e erro" (Gibbins e Adams 2001), desde o início o PAS trabalhou dentro de "padrões aceitáveis em Arqueologia Subaquática" (Dean 1988), com as técnicas de campo mais contemporâneas da disciplina, bem como conservou os artefatos e objetos dentro dos procedimentos mais atuais (Hamilton 1998). Atualmente a equipe busca o mesmo status da terceira geração (Gibbins e Adams 2001), a qualificação acadêmica e profissional em Arqueologia Subaquática.

No final de 2004 a equipe incorporou um arqueólogo terrestre, que encontrou um projeto funcionando corretamente em termos científicos, legais e éticos. Agora a equipe aperfeiçoa procedimentos e realiza estudos para sistematizar e consolidar os fundamentos práticos e teóricos do PAS.

Como advoga Dean (1988:ii), nas Normas sobre padrões aceitáveis em Arqueologia Subaquática, o que importa são os procedimentos, onde não pode haver "diferença fundamental entre arqueologia terrestre e subaquática, onde não pode haver justificativas para padrões arqueológicos distintos". A idéia data de 1966, quando Bass (1969:17), o "pai" da arqueologia subaquática científica, escreveu "que a arqueologia subaquática devia chamar-se simplesmente de 'arqueologia'. (...) A finalidade básica em todos estes trabalhos é a mesma. Tudo é arqueologia".

Destacados pesquisadores da Arqueologia Subaquática publicaram considerações parecidas. Para Barto Arnold III (1982:238), “qualquer arqueólogo competente em terra pode aprender a mergulhar com uma equipe profissional e, com algum treinamento especializado adicional, pode qualificarse para tratar com sítios subaquáticos". Para Dean (1988:16), "é muito mais fácil adquirir habilidade e experiência arqueológica em terra para, então, usá-la debaixo d'água". Cederlund (1995:11), concluiu que, "em essência," a principal corrente teórica da Arqueologia [terrestre] e da Arqueologia Marítima é a mesma". Hamilton (1996:729), considerou que a "Arqueologia Subaquática é meramente toda Arqueologia que é executada sob a água" e que ela "não possui uma teoria única para si mesma, excetuando para estudos especializados que envolvem evolução e tecnologia da construção de embarcações". Gould (2000:7) advogou que os métodos da Arqueologia Subaquática "são proporcionais às mesmas normas da Arqueologia terrestre".

O início da ONG PAS, sem um arqueólogo formalmente treinado para atuar sob a água, caracteriza a incipiência da Arqueologia Subaquática no Brasil, um país de enorme fronteira maritima $\mathrm{e}$ gigantesca rede hidrográfica. Contudo, como existe muito trabalho pela frente e um imenso patrimônio para preservar, o início da ONG PAS pretendeu superar as dificuldades de um país com escassos cientistas academicamente formados, cuja realidade é de 50 anos de atraso em relação aos países mais avançados na disciplina. Também mostra que pessoas motivadas pelo interesse histórico, pela ética preservacionista, pelo conhecimento das leis, por estudos autodidatas, com bom senso e inteligência, podem desenvolver pesquisas rigorosas e relevantes para o público e a ciência.

(9) Alguns, como Flatman (2003), consideram que o campo vem acumulando uma massa crítica que já permite reivindicar uma teoria específica da "arqueologia marítima", diferenciada da "arqueologia terrestre". 


\section{Referências bibliográficas}



2002 Underwater archaeological parks: a new perspective and challenge for conservation the Italian panorama. IJNA, 31 (1):83-88.

FLATMAN, J.

2003 Cultural biographies, cognitive landscapes and old dirty of boat: "theory" in maritime archaeology. IJNA, 32 (2):143-157.

FLECKER, M.

1996 Magnetometer survey of Malacca reclamation site. IJNA, 25 (2):122-134.

GARRISON, E.G

1989 A diachronic study of some historical and natural factors linked to shipwrecks patterns in the Northern Gulf of Mexico. Underwater Archaeology Proceedings from the Society for Historical Archaeology Conference. Baltimore: Society for Historical Archaeology Conference: 12-18.

(10) International Journal of Nautical Archaeology



1993 Interim report in the joint Sri Lanka-Australian maritime archaeological training research program, 1992-93. IJNA, 22 (4):331-343.

GRENIER, R.

2001 The ICOMOS International Committee on the Underwater Cultural Heritage. Papers presented at the $33^{\text {rd }}$ Annual Meeting of the Canadian Archaeological Association. Ontario: Ontario Archaeological Society: 232.

HAMILTON, D. L.

1998 Methods of conserving archaeological material from underwater sites. College Station: Texas A \& M University.

HAMILTON, D.L.

1996 Underwater Archaeology. B. Fagan (Ed.) The Oxford Companion to Archaeology. Oxford, Oxford University Press: 729-730. (http://nautarch.tamu.edu/class/ANTH605)

KENDERDINE, $\mathrm{S}$.

1994 Historic shipping on the River Murray, Australia: a guide to the shipwreck resource. IJNA, 23 (3):173-188.

MARSDEN, $\mathrm{P}$.

1994 A comparative look at records of twenty years of wreck archaeology. IJNA, 23 (2):155-158.

MAURO, F.

1975 Os espaços maritimos e a economia colonial brasileira in. F. Mauro. Do Brasil à America. São Paulo: Perspectiva.

MONTEIRO, P.A.

2003 A carta arqueológica subaquática dos Açores. http://nautarch.tamu. edu/shiplab/ Nautical Archaeology Program, Texas A\&M University.

NEGUERUELA, I.

2000 Managing the maritime heritage: the National Maritime Archaeological Museum and the Center for Underwater Research, Cartagena, Spain. IJNA, 29 (2):179-198.

O'KEEFE, P.J.

1996 Protection of the underwater cultural heritage: developments at UNESCO. IJNA, $25(3-4): 169-176$

OKOROKOV,A.V.

1993 Development of underwater archaeological investigations in Russia and the former Soviet Union. IJNA, 22 (3):267-273.

OXLEY, I.; O'REGAN, D.

2001 The marine archaeological resource. 
VIANA, A.; CORREA, N.S.; MOURA, M.L. Programa de Arqueologia Subaquática: o patrimônio cultural subaquático marinho do estado de Santa Catarina. Rev. do Museu de Arqueologia e Etnologia, São Paulo, 14: 387-391, 2004.

Whitheknights: Institute of Field Archaeologists Paper n. 4.

PEARSON, C.E.ET AL.

2003 Refining and revisiting the Gulf of Mexico outer continental shelf region highprobability model for historic shipwrecks. Final report. New Orleans: Minerals Management Service/U.S. Department of the Interior, 2003. v. 1, 2, 3

PINDER, D.; VALLEGA, A.

2003 The coastal cultural heritage and sustainable development: a introduction. Journal of Cultural Heritage, 4(1):3-4.

PRADOS, E.

1994 An archaeological investigation of Sira Bay, Aden, Republic of Yemen. IJNA, 23 (4):297-307.

Recebido para publicação em 15 de dezembro de 2004.
QUINN, R; COOPER, A.J.A.G.; WILLIANS, B.

2000 Maritime geophysical of the inshore coastal waters of Northern Ireland. IJNA, 29 (2):294-298. SCHLICHTHERLE, H.; KRAMER, W.

1996 Underwater archaeology in Germany. IJNA, 25 (2):141-151.

SMITH, H.D.; COUPER, A.D

2003 The management of the underwater cultural heritage. Journal of Cultural Heritage, 4:25-33. VALLEGA,A.

2003 The coastal cultural heritage facing coastal management. Journal of Cultural Heritage, (1) 4:5-24.

WERZ, B.E.J.S

1993 Shipwrecks of Roben Island, South Africa: a cultural exercise in resource management in underwater environment. IJNA, 22 (3):245-256. 